\title{
EXAMINATION METHOD OF THE EFFECT OF THE INCIDENCE ANGLE OF LASER BEAM ON DISTANCE MEASUREMENT ACCURACY TO SURFACES WITH DIFFERENT COLOUR AND ROUGHNESS
}

\author{
Método para avaliar o ângulo de incidência de um feixe laser na acurácia da \\ medida de distâncias em superfícies com diferentes cores e rugosidades
}

\begin{abstract}
Karol Daliga ${ }^{1}$
Zygmunt Kurałowicz ${ }^{1}$

${ }^{1}$ Faculty Of Civil And Environmental Engineering, Gdansk University Of Technology, Gdansk, Poland. kardali1@pg.gda.pl; zkur@pg.gda.pl
\end{abstract}

\begin{abstract}
:
Interest in the influence of the incidence angle of a laser beam to distance measurements can be seen in many areas of science and technology: geodesy, glaciology, archaeology, machine automation, and others. This paper presents results of measurements of the effect of the incidence angle of a laser beam to distance measurements to the surfaces of different colour and roughness by Topcon's electro-optical total station with an accuracy of $3 \mathrm{~mm}$. Measurement method and the method of elimination of test stand errors are presented. The results of measurements have been analysed and the influence of selected factors (surface colour and roughness, lack of instrument rectification) on the distance measurement have been discussed. It is also shown the critical incidence angle above which it can be impossible to measure distances to reflective foil with tested total station.
\end{abstract}

Keywords: Laser rangefinder, distance measurements, incidence angle.

\section{Resumo:}

O interesse pela influência do ângulo de incidência de um feixe laser para medida de distâncias pode ser visto em muitas áreas da ciência e tecnologia: geodésia, glaciologia, arqueologia, automação, entre outras. Este artigo apresenta resultados de medidas do efeito do ângulo de incidência de um feixe laser para medida de distância em superfícies de diferentes cores e rugosidades utilizando uma estação total eletro-óptica Topcon, com acurácia de $3 \mathrm{~mm}$. Descrevem-se os métodos de medida e de eliminação dos erros padrão. Os resultados das medidas foram analisados e discute-se a influência de alguns fatores (cor da superfície, rugosidade e fala de retificação do instrumento) na medida das distâncias são discutidos. Também se apresenta o ângulo de incidência crítico acima do qual é impossível medir distâncias até um alvo refletivo, considerando o equipamento utilizado. 
Palavras-chave: distanciômetro laser, medida de distância, ângulo de incidência.

\section{Introduction}

Nowadays in many fields of science and technology distance measurements are made using electro-optical rangefinders (laser rangefinders). In case of measurements of 'smaller' distances (the order of centimetres), rangefinders based on the principle of triangulation can be used. In case of measurements of 'larger' distances (in order of metres, tens and hundreds of metres, up to kilometres) phase and pulse rangefinders are used. For example agricultural machines are equipped (experimentally) with laser rangefinders (in the form of laser scanners) (Coen et al. 2008).

Distance measurements are carried out in different environmental conditions. If the measurements are to be reliable and accurate, it is important to know how environmental conditions affect the measurements. In addition, the quality of the measurement can be affected by the surface of the element measured. For example: the measured object/element can have a surface with different colours (e.g. grey concrete chimney with red and white horizontal lines), and in the space between the laser light source (rangefinder, total station, laser scanner) and the target surface there may be pollination, different humidity and temperature or variable electric field (Bryś 2012). These environmental factors, affecting the measurement results, can occur in both open and enclosed space i.e. in the production halls. Laser beam from rangefinder can also 'pass' through transparent barriers during measurements (Daliga 2013; Daliga and Kurałowicz 2014).

This article presents the results of a study of the impact of changes of the incidence angle for laser beam aimed at the surfaces of different colour and roughness on distance measurements, assuming a constant distance $D$ between laser light source and the measured target. The potential impact of a glass element close to the target on distance measurements has also been examined. During the research reflectorless distance measurements (fine mode) to targets with different surface colour and roughness were performed, which depicted the texture of the surfaces of real measured objects or elements in the field. These types of studies are also of interest to other researchers from various fields of science i.e. (Prokop 2008; Hodge 2010; Soudarissanane et al. 2011; Beshr and Abo Elnaga 2011; Ehlert and Heisig 2013).

\section{Research description}

\subsection{Description of measuring station and measurements}

The test stand consists of 2 measuring positions (total station and theodolite position), and was located in a room not exposed to shocks, dimly lit, with air temperature between $18{ }^{\circ} \mathrm{C}$ and $21 \mathrm{C}$ and of relative humidity of air from $45 \%$ to $60 \%$. At first position (1) was equipped with a tripod with total station (as range finder) with a fixed height relative to the accepted reference. The second position (2) was equipped with a target in the form of specially prepared test plates 
measuring $5 \mathrm{~cm} \times 10 \mathrm{~cm}$, placed on theodolite (at rotation axis). Total station Topcon ES-107 with reflector measurement accuracy $(3+2 \mathrm{~mm} / \mathrm{km}) \mathrm{mm}$ and reflectorless measurements $(3+2 \mathrm{~mm} / \mathrm{km}) \mathrm{mm}$, and theodolite Theo $010 \mathrm{~A}$ with read accuracy from the horizontal wheel $2^{\mathrm{cc}}$ (1") were used. The horizontal distance between the rotation axis of the total station and the rotation axis of the theodolite was $D=30,00 \mathrm{~m}$ (Figure 1). In order to obtain the maximum range of the horizontal incidence angle of the laser beam on the tested plates, range from -80 to +80 $\operatorname{grads}\left(1 \operatorname{grad}=0.9^{\circ}=\pi / 200 \mathrm{rad}\right)$ was used (angle of incidence is the angle between the normal to the surface of the plate and the direction of the laser light beam). The angle was changed every 10 grads and, in addition, it was taken for angles of incidence of the beam: $5 ; 2 ; 1 ; 0,5 ;-0,5 ;-1$; -2 and -5 grads. For the adopted incidence angles 20 measurements of the distance were made each time, and then averaged. Each distance measurement was made with the same (fixed) position scope of total station (and laser light source).

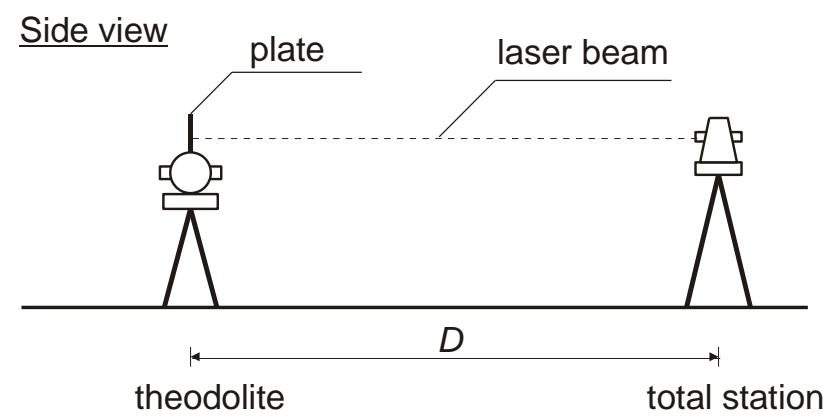

Top view

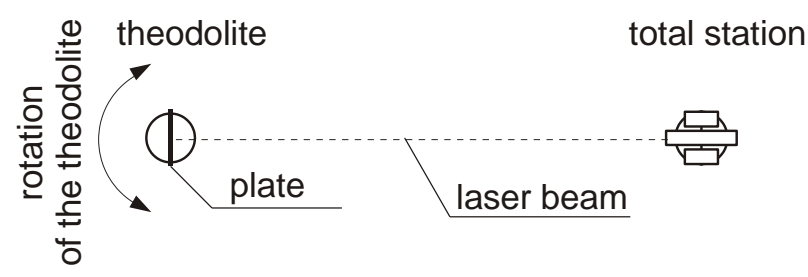

Figure 1: Scheme of the test stand

Plates of different colour and surface roughness were placed on the theodolite in such a way that their front surface was adjacent to the "stop bar" attached to the theodolite (Figure 2). Due to this the surface of the sample on which the laser light emitted by total station falls, was located in the "same place" relative to theodolite. It was also possible to modify the plate mounting in the way which would allow to tilt the plates vertically. 


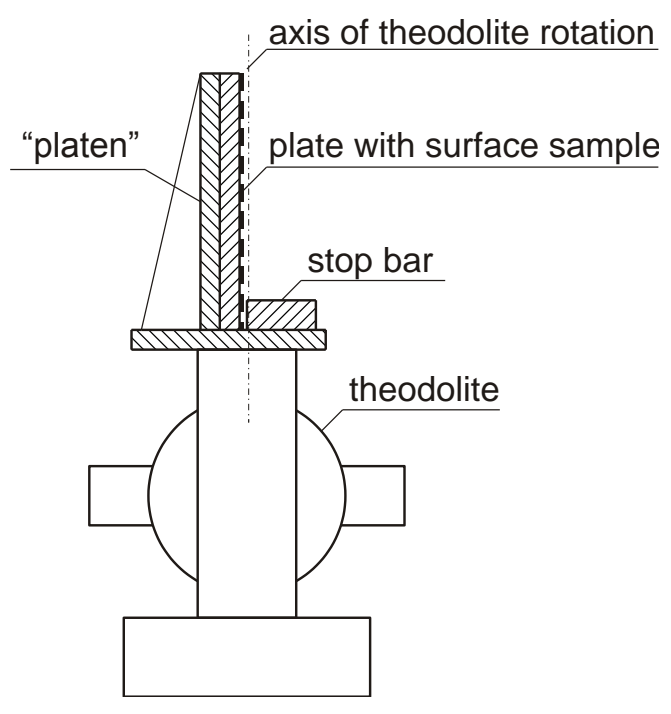

Figure 2: Scheme of plate mounting to theodolite

At the time of the measurements it was also examined if the theodolite lens facing total station has an effect on the measurement of the distance to the plates (i.e. in practice, if a glass element close to the measured target can affect the measurement of the distance to it). Vertical distance between the aiming point on the plate and theodolite telescope was $15 \mathrm{~cm}$. The angle between the total station aiming line of sight and the line linking theodolite telescope and the scope of total station was around 1.75' (Figure 3). In order to verify the impact of the glass component on the distance measurement 6 complete measuring series were made with the exposed theodolite lens and one measuring series with covered theodolite lens.

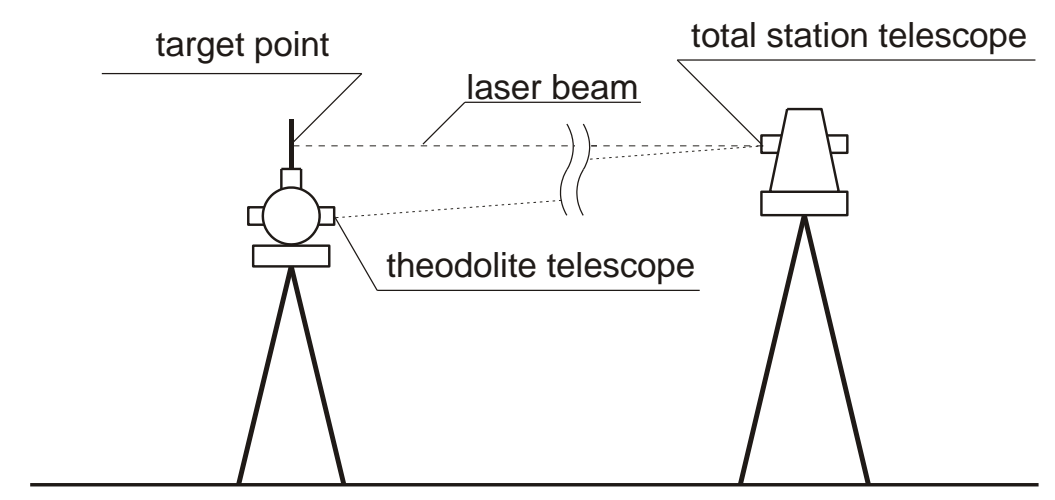

Figure 3: Scheme of relative position of theodolite, tested plate (target) and total station

\subsection{Description of tested plates of different colour and roughness}

40 plates were used for distance measurements, one plate with Topcon's reflective foil attached and 39 plates of different colour and surface roughness, marked with letter "P" and a number. Samples had 6 different roughness values, marked basing on ISO 6344-1 "Coated abrasives Grain size analysis - Part 1: Grain size distribution test". The surface roughness of the sample decreases with the increase in the number of the letter P (i.e. sample P120 has a smaller 
roughness than sample P40). Samples marked "P Bn" had smooth surfaces. Other marked samples were as follows:

- $\quad$ "The P180" - included up to $2 \%$ of macro grains of the size from $150 \mu \mathrm{m}$ to $106 \mu \mathrm{m}$ (not smaller than), $(15 \pm 5) \%$ of grains to $90 \mu \mathrm{m},(62 \pm 12) \%$ of grains of the size to $75 \mu \mathrm{m}$ and $90 \%$ of grains to $63 \mu \mathrm{m}$.

- $\quad$ "P120" - included up to 7\% of macro grains of the size from $212 \mu \mathrm{m}$ to $150 \mu \mathrm{m}$ (not smaller than), $(42 \pm 8) \%$ of grains to $125 \mu \mathrm{m},(86 \pm 6) \%$ of grains to $106 \mu \mathrm{m}$ and $96 \%$ of grains to $90 \mu \mathrm{m}$.

- $\quad$ "P80" - included up to 3\% of macro grains of the size from $355 \mu \mathrm{m}$ to $250 \mu \mathrm{m}$ (not smaller than), $(26 \pm 6) \%$ of grains to $212 \mu \mathrm{m},(75 \pm 9) \%$ grain sizes up to $180 \mu \mathrm{m}$ and $96 \%$ of grains up to $150 \mu \mathrm{m}$.

- $\quad$ "P40" - included up to 7\% of macro grains about of the size from $720 \mu \mathrm{m}$ to $500 \mu \mathrm{m}$ (not smaller than), $(42 \pm 8) \%$ of grains to $425 \mu \mathrm{m},(86 \pm 6) \%$ of the grains to $355 \mu \mathrm{m}$ and $96 \%$ of grains up to $300 \mu \mathrm{m}$.

- $\quad$ "P24" - included up to $1 \%$ of macro grains of the size from $1.4 \mathrm{~mm}$ to $1 \mathrm{~mm}$ (not smaller than), $(14 \pm 4) \%$ of grains to $850 \mu \mathrm{m},(61 \pm 9) \%$ of grains to $710 \mu \mathrm{m}$ and $92 \%$ of grains with sizes up to $600 \mu \mathrm{m}$.

Samples were performed on smooth PVC plates $(5 \mathrm{~mm}$ thick). On plates were glued (two component glue) abrasive paper with specific size of grains. When glue dried, primer layer and proper colour layer were applied by airbrush.

\subsection{Reduction method of the test stand systematic errors}

Investigating the effect of the incidence angle of the laser beam on the measurement of the distance needed to take into account possible errors coming from the following sources of systematic errors being consequences of the adopted methodology of research:

a) laser light beam direction does not cross the vertical axis of rotation of the test plate, Figure 4, (error depends on the incidence angle);

b) vertical axis of rotation and the surface of the plate do not lie in one plane, Figure 5 (error depends on the incidence angle);

c) the presence of the precession of the axis of rotation of the theodolite and its phase $\varphi_{0}$, Figure 6 (error depends on the incidence angle); 
d) zero angle setting in respect of which the other incidence angles were measured (this systematic error is independent of the incidence angle).

Moreover, because the measurement was carried out in one total station scope position, there may be a systematic error of distance measurement. This error was not taken into account because it does not affect the dependence of distance measurements when the incidence angle was changed. It only causes apparent remoteness of the plates from the total station.

In order to eliminate the impact of existing systematic errors associated with the way of changing the incidence angle of the light laser beam, a theoretical model was developed - the equation describing the identified errors (systematic error function). For individual sources of systematic errors the principle of superposition was applied.

The first analysed source of systematic error was the lack of intersection of the plate's rotation axis with the direction of the laser light beam (Figure $4 \mathrm{a}$ and Figure $4 \mathrm{~b}$ ).

a)

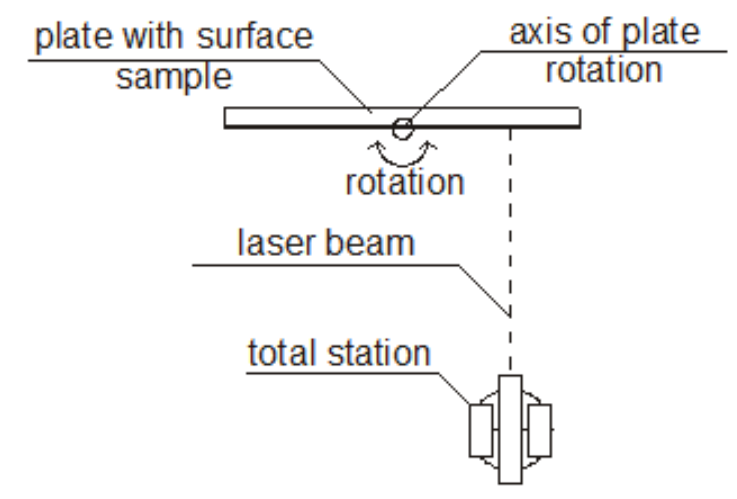

b)

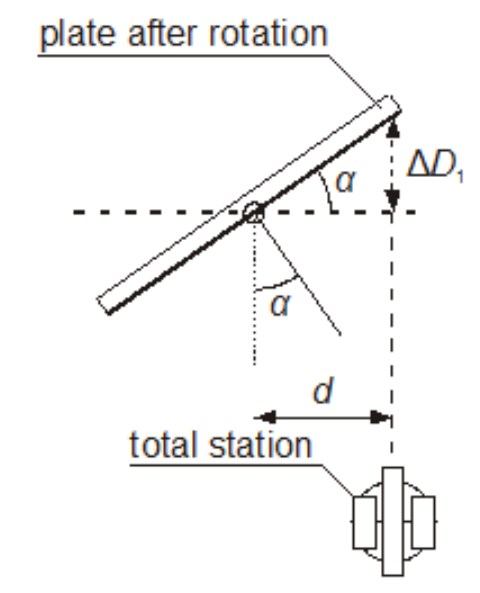

Figure 4: Scheme of systematic error source associated with the lack of intersection of the rotation axis and the direction of the laser light beam (a) and a scheme to calculate distance changes $\Delta D_{1}$ (b)

Distance change value $\Delta D_{1}$ can be calculated by the Equation 1:

$$
\Delta D_{1}=d \cdot \operatorname{tg} \alpha
$$

where: $\Delta D_{1}$ - change of distance related to the lack of intersection of the rotation axis and the direction of the laser beam; $d$ - offset of laser beam direction from rotation axis of the plate; $\alpha-$ incidence angle of laser beam on the plate.

The second source of systematic error included in the "systematic error function" was the fact that the rotation axis of plate and the surface on which the laser beam drops, were not in one plane (Figure 5a and Figure 5b). 
a)

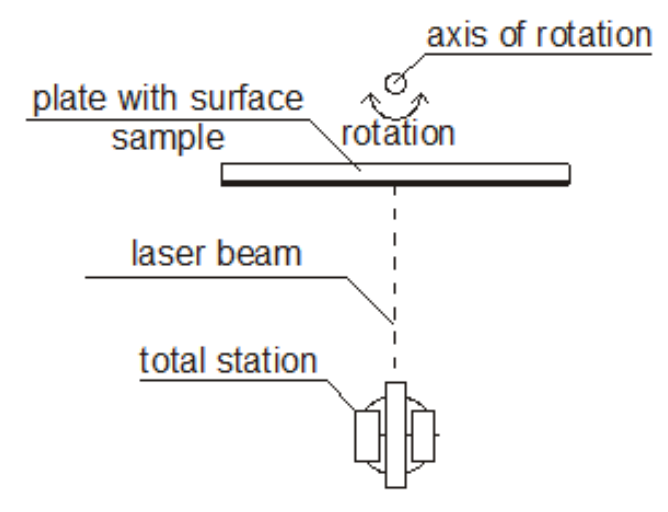

b)

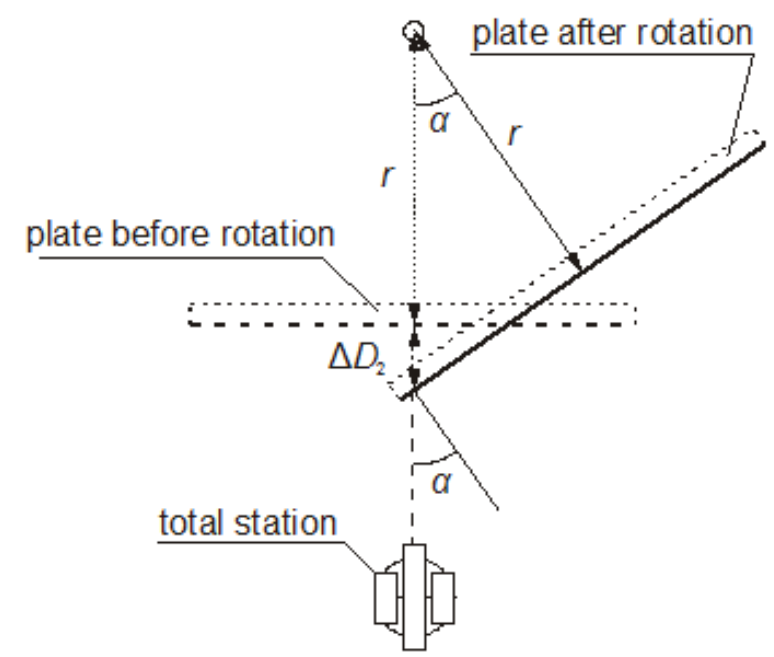

Figure 5: Scheme of the sources of systematic error associated with offset of rotation axis from the surface on which laser beam drops (a) and a scheme to calculate distance changes $\Delta D_{2}$ (b)

Distance change value $\Delta D_{2}$ can be calculated by the Equation 2:

$$
\Delta D_{2}=\frac{r \cdot(1-\cos \alpha)}{\cos \alpha}
$$

where: $\Delta D_{2}$ - change of distance related to offset of rotation axis from the surface on which laser beam drops; $r$ - the offset of the rotation axis of the plate from the surface on which laser beam drops; $\alpha$ - incidence angle of laser beam on the plate.

The third source of systematic error was the precession of the rotation axis of the theodolite and its phase $\varphi_{0}$ (Figure 6a and Figure 6b).

a)

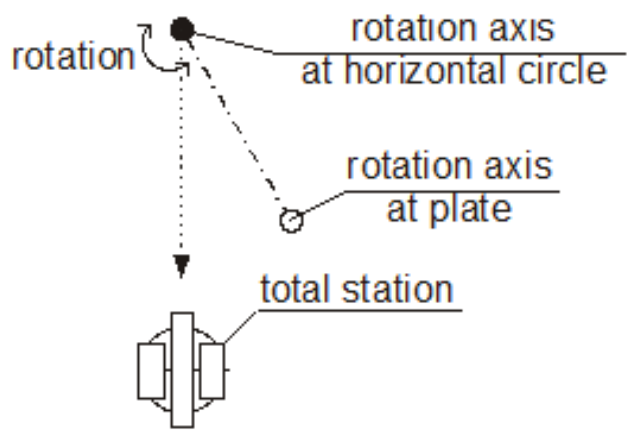

b)

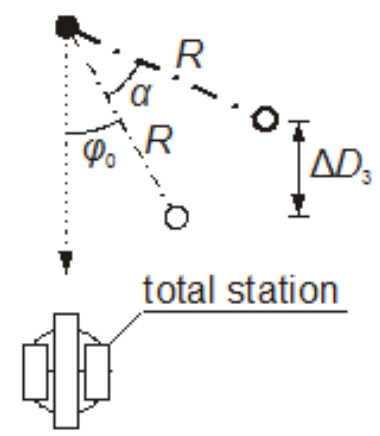

Figure 6: Scheme of the systematic error source associated with the precession of rotation axis (a) and a scheme to calculate distance changes $\Delta D_{3}$ (b)

Distance change value $\Delta D_{3}$ can be calculated by the Equation 3:

$$
\Delta D_{3}=R \cdot\left[\cos \varphi_{0} \cdot(1-\cos \alpha)+\sin \varphi_{0} \cdot \sin \alpha\right]
$$


where: $\Delta D_{3}$ - distance change associated with the precession of the rotation axis and the phase; $R$ - horizontal distance between a point on the rotation axis at the basis of theodolite and point on the rotation axis at the place of laser beam impact on the plate; $\varphi_{0}$ - initial precession phase of the rotation axis; $\alpha$-incidence angle of the laser beam on the plate.

The setting of zero incidence angle of laser beam was done by iterative aiming into the centre of total station telescope (by theodolite) and into the centre of theodolite telescope (by total station). For this reason, it is assumed that the error caused by not perpendicular impact of the laser beam for the adopted incidence angle $0^{\mathrm{g}}$ was very small and can be omitted.

The "systematic error function" associated with the way of setting the incidence angle of the laser beam on the sample, can be written by (4) and after substituting Equations 1 to 3 can be written by Equation 5:

$$
\begin{gathered}
\Delta D=\Delta D_{1}-\Delta D_{2}+\Delta D_{3} \\
\Delta D=d \cdot \operatorname{tg} \alpha-\frac{r \cdot(1-\cos \alpha)}{\cos \alpha}+R \cdot\left[\cos \varphi_{0} \cdot(1-\cos \alpha)+\sin \varphi_{0} \cdot \sin \alpha\right]
\end{gathered}
$$

where: $\Delta D$ - total systematic error associated with the way of setting incidence angle of the laser beam.

Assuming that the systematic error associated with distance measurement in one telescope position was skipped, the measured distance to the plate, depending on the incidence angle of the laser beam on the plate, can be written by Equation 6:

$$
D=D_{0}+\Delta D
$$

where: $D$ - measured distance to the plate; $D_{0}-$ the distance between total station and the rotation axis of theodolite near horizontal circle.

Equation 6 was the approximation function for measurements results. Based on this function, values of systematic errors were calculated for every incidence angle of laser beam. Then, distance measurements data was reduced by calculated values of systematic errors. The approximation of measuring points by Equation 6 was made using OriginPro 9.0, OriginLab. Measurement data prepared in the described way were analysed.

\subsection{Example of stand systematic error reduction process}

For example, it was described a reduction process for systematic errors caused by imperfections of test stand for acquired data. The starting point are an example results of measurements for which are taken into account, and reduced, additional sources of errors.

Raw measurement data for measured distance as relation of incidence angle of laser beam $D(\alpha)$ was shown on Figure 7. This measurement points were approximated by function (6) and the 
following parameters were given: $d=0.0023 \mathrm{~m}, r=-0.0005 \mathrm{~m}, R=-0,001 \mathrm{~m}, \varphi_{0}=11^{\mathrm{g}}$, $D_{0}=29.999 \mathrm{~m}$.

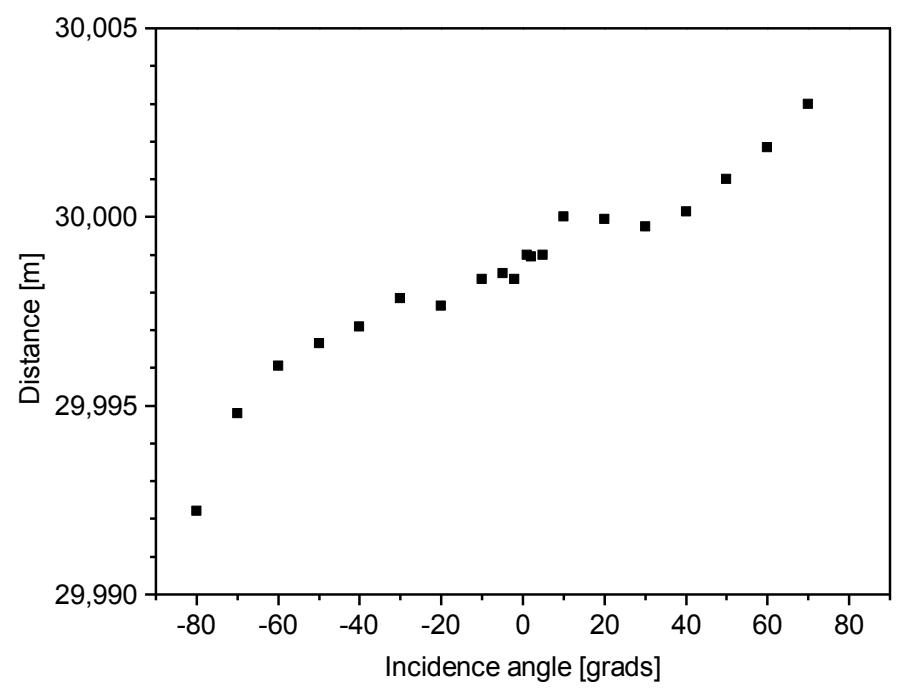

Figure 7: Example raw measurement data for example of systematic error reduction process

Figure 8 presents measurement data reduced by error associated with the lack of intersection of the rotation axis and the direction of the laser light beam calculated by using Equation 7:

$$
D_{1}=D-\Delta D_{1}
$$

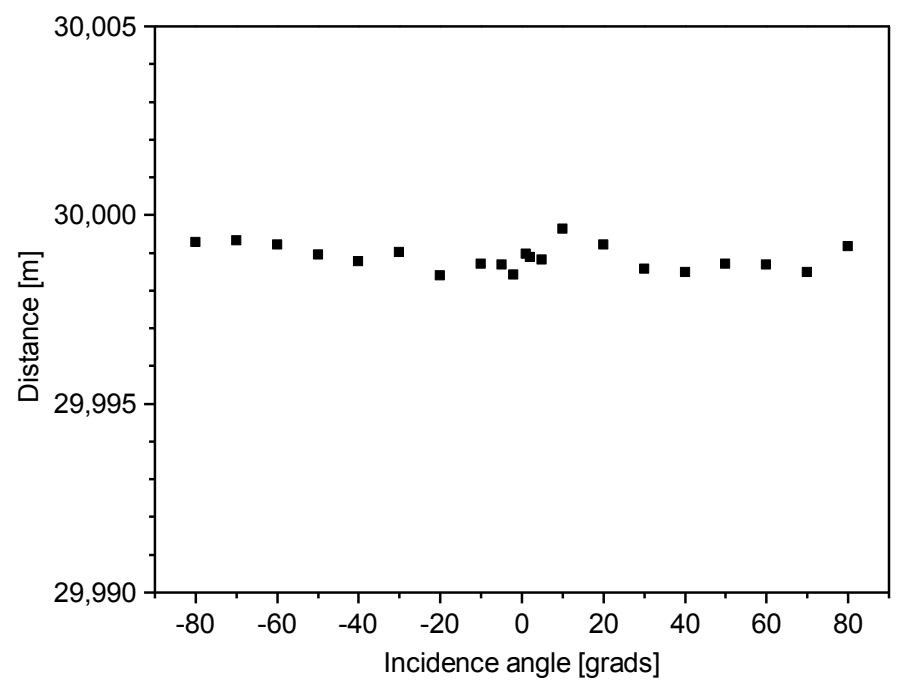

Figure 8: Measurement data reduced by error associated with the lack of intersection of the rotation axis and the direction of the laser light beam

Figure 9 presents measurement data additionally reduced by error associated with offset of rotation axis from the surface on which laser beam drops calculated by using Equation 8:

$$
D_{2}=D_{1}-\Delta D_{2}
$$




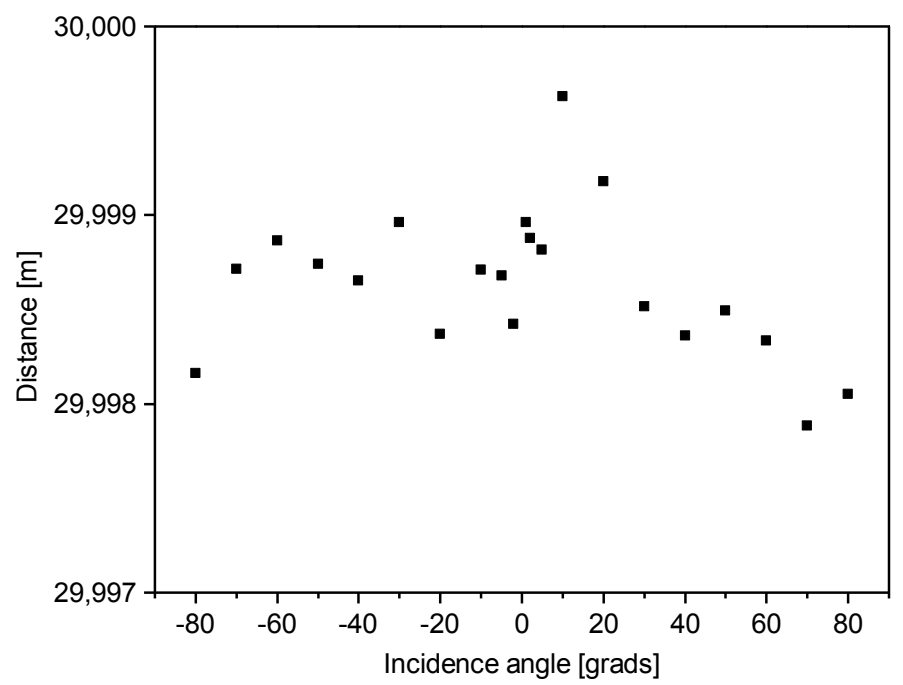

Figure 9: Measurement data additionally reduced by error associated with offset of rotation axis from the surface on which laser beam drops

Figure 10 presents measurement data additionally reduced by error associated with the precession of rotation axis calculated by using Equation 9. Fluctuations of measurement data are less than accuracy of total station's rangefinder $(3 \mathrm{~mm})$.

$$
D_{3}=D_{2}-\Delta D_{3}
$$

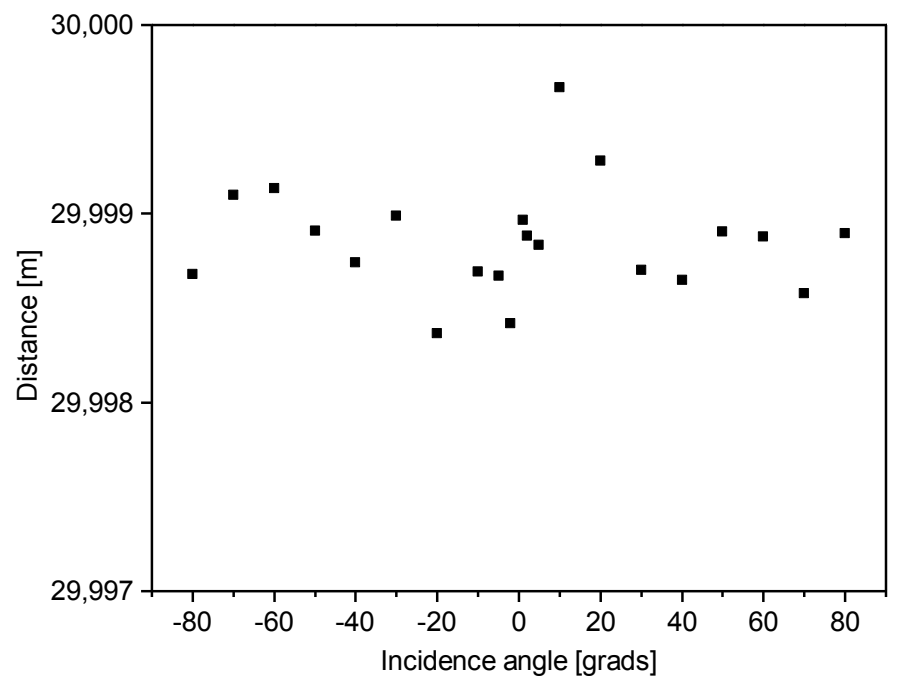

Figure 10: Measurement data additionally reduced by error associated with the precession of rotation axis

Figures presented in this paper presents measurement data with reduced impact of systematic errors calculated by procedure shown above. 


\section{The results of the distance measurements}

The results of distance measurements for plates of different colour, depending on the incidence angle and surface roughness, after reducing the impact of systematic errors, are presented in Table 1 and shown on the graphs (Figure 11 to Figure 18). Table 1 contains the average distance to the samples (arithmetic mean of measurements for all incidence angles, skipping range from $0.5^{\mathrm{g}}$ to $+0.5^{\mathrm{g}}$ due to the presence of the "peak"), the standard deviation of the mean (without taking into account the accuracy of the distance measurement by the used total station) and the height of the observed "peak" for incidence angle $0^{\mathrm{g}}$. The height of the "peak" was calculated as measured distance to the sample for the incidence angle of $0^{\mathrm{g}}$, reduced by the average distance to the sample. The given uncertainty of peak height was calculated for a confidence level of about 95\% (taking into account the accuracy of the total station's distance measurement).

Table 1: Summary of results of studies on the effects of changing the incidence angle of the laser beam to distance measurements to the surface of different colour and roughness

\begin{tabular}{|c|c|c|c|c|c|}
\hline $\begin{array}{c}\text { Measurement } \\
\text { series }\end{array}$ & $\begin{array}{l}\text { Colour of tasted } \\
\text { plate }\end{array}$ & $\begin{array}{l}\text { Description of } \\
\text { plate's } \\
\text { roughness }\end{array}$ & $\begin{array}{c}\text { Average distance } \\
\text { to the plate } \\
{[\mathrm{m}]}\end{array}$ & $\begin{array}{c}2 \text { standard } \\
\text { deviation of the } \\
\text { mean } 2 \cdot s(q) \\
\text { [mm] }\end{array}$ & $\begin{array}{c}\text { Peak height } \\
\text { [mm] }\end{array}$ \\
\hline \multirow{6}{*}{ I } & \multirow{6}{*}{ White } & $\mathrm{P} B \mathrm{n}^{*}$ & 29,9981 & 0,2 & $-0,2 \pm 4,2$ \\
\hline & & P180* & 29,9981 & 0,1 & $0,0 \pm 4,2$ \\
\hline & & P120* & 29,9984 & 0,1 & $-0,2 \pm 4,2$ \\
\hline & & P80* & 29,9984 & 0,1 & $-0,2 \pm 4,2$ \\
\hline & & P404 & 29,9985 & 0,1 & $-0,5 \pm 4,2$ \\
\hline & & P24* & 29,9980 & 0,2 & $4,7 \pm 4,2$ \\
\hline \multirow{6}{*}{ II } & \multirow{6}{*}{ Black } & $\mathrm{PB} \mathrm{n}^{*}$ & 30,0018 & 0,5 & $11,8 \pm 4,2$ \\
\hline & & $\mathrm{P} 180^{\circ}$ & 30,0043 & 0,3 & $12,3 \pm 4,2$ \\
\hline & & $\mathrm{P} 120^{*}$ & 30,0045 & 0,4 & $12,9 \pm 4,2$ \\
\hline & & P80* & 30,0051 & 0,4 & $15,5 \pm 4,2$ \\
\hline & & $\mathrm{P} 40^{4}$ & 30,0049 & 0,4 & $13,1=4,2$ \\
\hline & & P24* & 30,0069 & 0,4 & $17,5 \pm 4,2$ \\
\hline \multirow{2}{*}{ III } & \multirow{2}{*}{$\begin{array}{c}\text { Topcon's reflective } \\
\text { foil }\end{array}$} & $\mathrm{RL}^{*}$ & 29,9981 & 0,3 & - \\
\hline & & $\mathbb{R}^{*}$ & 29,9989 & 0,2 & - \\
\hline \multirow{6}{*}{ IV } & \multirow{6}{*}{ Red } & P Bn* & 30,0000 & 0,1 & $5,4 \pm 4,2$ \\
\hline & & P180* & 29,9987 & 0,1 & $11,2 \pm 4,2$ \\
\hline & & P120* & 30,0000 & 0,0 & $9,8 \pm 4,2$ \\
\hline & & $\mathrm{P} 80^{*}$ & 30,0006 & 0,1 & $9,4 \pm 4,2$ \\
\hline & & $\mathrm{P} 40^{4}$ & 30,0006 & 0,1 & $9,0 \pm 4,2$ \\
\hline & & P24* & 29,9990 & 0,0 & $13,9 \pm 4,2$ \\
\hline \multirow{7}{*}{$\mathrm{v}$} & \multirow{7}{*}{ Light blue } & $\mathrm{P} B \mathrm{n}^{*}$ & 29,9993 & 0,2 & $6,0 \pm 4,2$ \\
\hline & & $\mathrm{P} 180^{*}$ & 29,9993 & 0,2 & $10,8 \pm 4,2$ \\
\hline & & $\mathrm{P} 120^{*}$ & 29,9995 & 0,1 & $10,8 \pm 4,2$ \\
\hline & & P80* & 29,9997 & 0,1 & $10,9 \pm 4,2$ \\
\hline & & $\mathrm{P} 40^{*}$ & 29,9997 & 0,2 & $10,8 \pm 4,2$ \\
\hline & & P24* & 30,0015 & 0,1 & $11,5 \pm 4,2$ \\
\hline & & $\mathrm{P} 24^{44}$ & 30,0015 & 0,1 & $0,7 \pm 4,2$ \\
\hline \multirow{6}{*}{ VI } & \multirow{6}{*}{ Light green } & $\mathrm{PBn}^{* 4}$ & 29,9976 & 0,1 & $0,2 \pm 4,2$ \\
\hline & & P180*4 & 29,9977 & 0,1 & $0,3 \pm 4,2$ \\
\hline & & $\mathrm{P} 120^{4 *}$ & 29,9977 & 0,1 & $0,3 \pm 4,2$ \\
\hline & & $\mathrm{P} 80^{4 *}$ & 29,9979 & 0,1 & $0,0 \pm 4,2$ \\
\hline & & $\mathrm{P} 40^{4 *}$ & 29,9978 & 0,1 & $0,3 \pm 4,2$ \\
\hline & & $\mathrm{P} 24^{4 *}$ & 29,9979 & 0,1 & $0,4 \pm 4,2$ \\
\hline
\end{tabular}

\footnotetext{
* distance measurement with exposed theodolite's lens (the influence of glass element on distance measurement),

** distance measurement with covered theodolite's lens.
}

Bol. Ciênc. Geod., sec. Artigos, Curitiba, v. 22, no3, p.420-436, jul-set, 2016. 
Basing on the data compiled in Table 1 and Figure 11 to Figure 18, it can be seen that the "peak" for the measured distance to the plate only occurs when the theodolite's lens was exposed and the reflectance of light for the sample was smaller than the coefficient of reflection of light for the lens in the telescope. In the limit of measurement uncertainty, it can be concluded that the "peak" height was mainly associated with the coefficient of reflection of light for the plate, and not with its roughness.

For black plates, within the accuracy of the instrument $(3 \mathrm{~mm})$ and after reduction of test stand errors, the angle of incidence did not significantly influence distance measurements (Figure 11). Some effect of incidence angle can be observed for the smooth sample (P Bn), which decreases when surface roughness increases. The increase in surface roughness caused an apparent increase in the distance between the test surface and the total station (from $30.002 \mathrm{~m}$ to $30.007 \mathrm{~m}$ ).

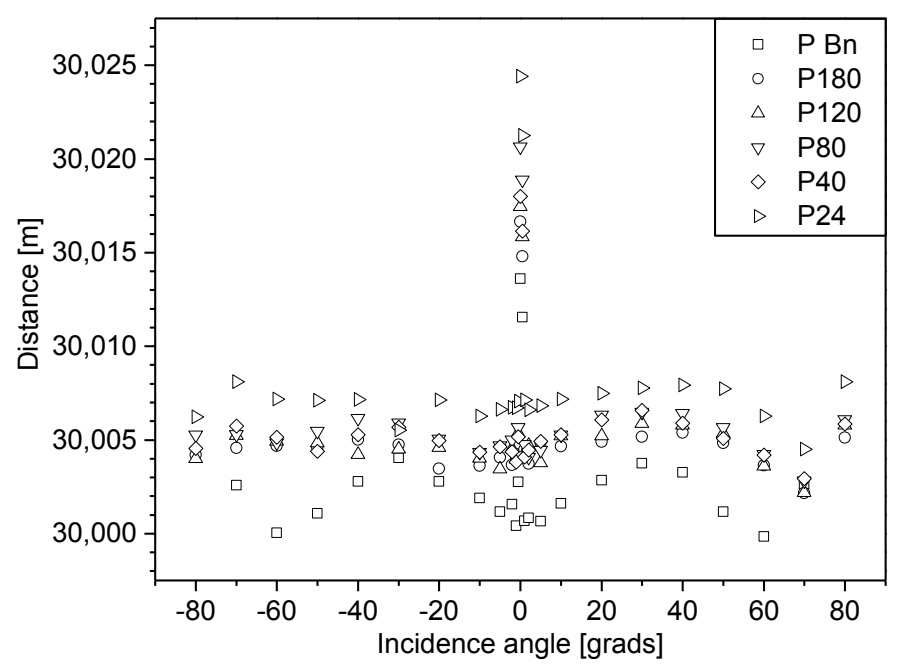

Figure 11: Measured distance to black plates of varying roughness, depending on the incidence angle of the laser beam (measurement uncertainty $-3 \mathrm{~mm}$ )

For white plates, within the accuracy of the instrument $(3 \mathrm{~mm})$ and after reduction of test stand errors, the incidence angle and roughness didn't affect the distance measurements (Figure 12).

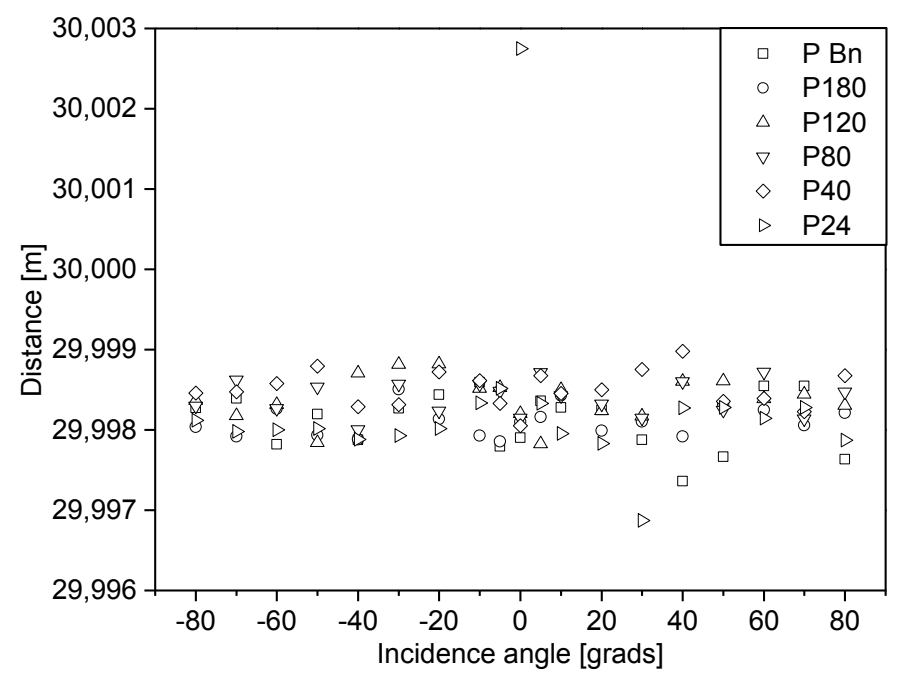

Figure 12: Measured distance to white plates of varying roughness, depending on the incidence angle of the laser beam (measurement uncertainty $-3 \mathrm{~mm}$ ) 
For Topcon's reflective foil and reflectorless measurements (RL), within the accuracy of the instrument $(3 \mathrm{~mm})$ and after reduction of test stand errors, the incidence angle didn't influence significantly the distance measurements (Figure 13).

For Topcon's reflective foil and reflector measurements (IR), within the accuracy of the instrument $(3 \mathrm{~mm})$ and after reduction of test stand errors, the incidence angle didn't affect the distance measurement (Figure 13). However, reduction of the incidence angle up to about 50 grads occurred. Above this angle, the instrument displayed the message that measurements were impossible.

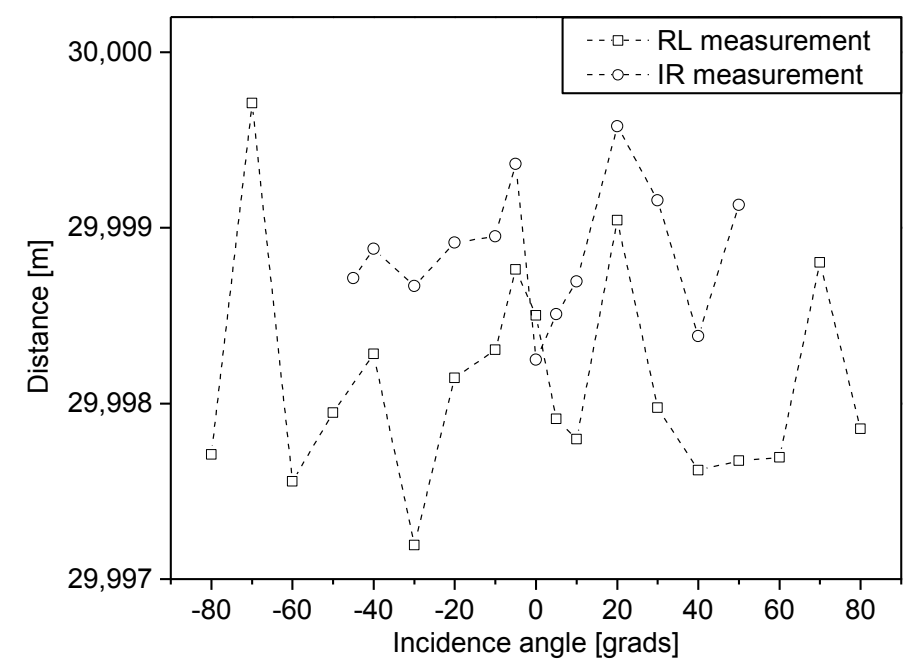

Figure 13: Measured distance to the Topcon's reflective foil depending on the incidence angle of the laser beam (measurement uncertainty $-3 \mathrm{~mm}$ )

For grey plates, within the accuracy of the instrument $(3 \mathrm{~mm})$ and after reduction of test stand errors, the incidence angle and roughness didn't affect the distance measurements (Figure 14).

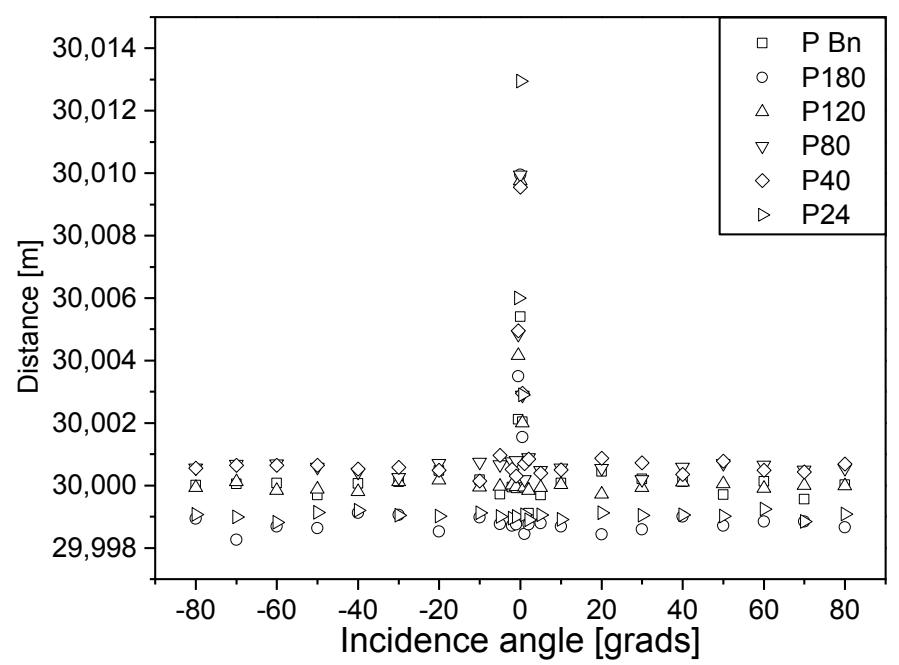

Figure 14: Measured distance to red plates of varying roughness, depending on the incidence angle of the laser beam (measurement uncertainty $-3 \mathrm{~mm}$ )

For light blue plates, within the accuracy of the instrument $(3 \mathrm{~mm})$ and after reduction of test stand errors, the incidence angle didn't affect the distance measurements (Figure 15). Increased surface roughness caused the apparent increase in the distance between the surface and the total 
station (from $29.999 \mathrm{~m}$ to $30.002 \mathrm{~m}$ ). The increase of the distance, however, was within the limits of the instrument's accuracy.

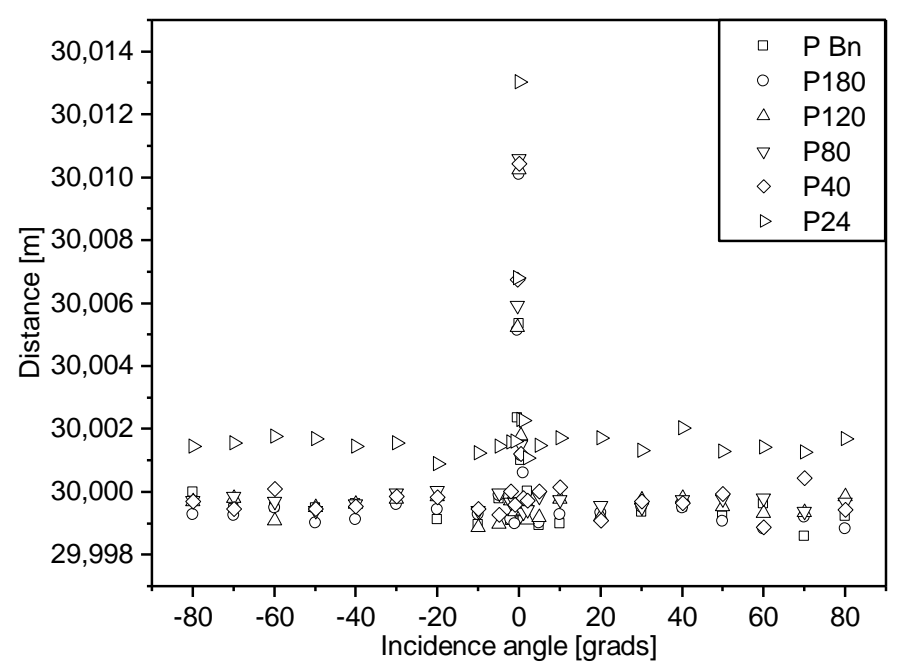

Figure 15: Measured distance to light blue plates of varying roughness, depending on the incidence angle of the laser beam (measurement uncertainty $-3 \mathrm{~mm}$ )

For light green plates, within the accuracy of the instrument $(3 \mathrm{~mm})$ and after reduction of test stand errors, the incidence angle and roughness didn't affect the distance measurements (Figure 16).

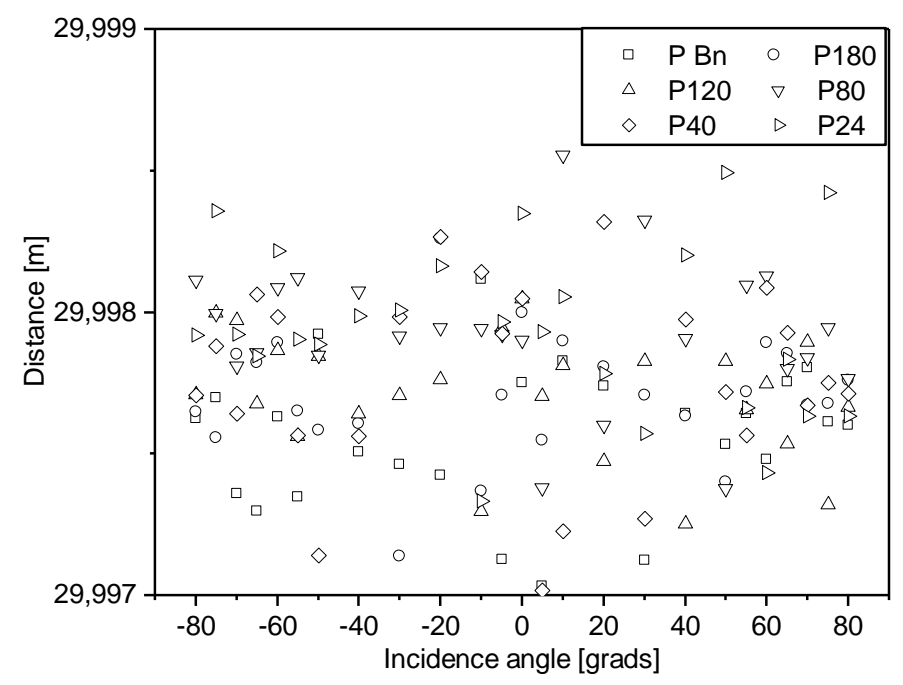

Figure 16: Measured distance to light green plates of varying roughness, depending on the incidence angle of the laser beam (measurement uncertainty $-3 \mathrm{~mm}$ )

\section{The analysis of the results and conclusions}

The studies performed show that colour, surface roughness and incidence angle can affect distance measurement by total station. 
In addition, it can be concluded that with the decrease of the of reflection coefficient of the surface the measurement time increases. Distance measurement for "dark" plates required more time than the distance measurement to "bright" surfaces. Time of distance measurement to black plates was the longest (up to $4.5 \mathrm{~s}$ ), while time of measurement to white plates was significantly shorter (about $2.0 \mathrm{~s}$ ). Time of distance measurement for Topcon's reflective foil was similar to measurement time of white plate (about $2.0 \mathrm{~s}$ ). It should be noted that during distance measurements reflection coefficient for the light "emitted" by the rangefinder is important, but not for "white light".

It was noted that the increase of surface roughness causes the apparent increase in the distance between the test surface and total station. One of the reasons is the fact that part of the light falls on the outer edges of the grains, and some reaches closer to the basis of grains. As it was assumed that the face of the sample should be in a constant position, so, when the size of grains went up, the distance to the ground of grains increased. The apparent increase in distance can also be associated with the light reflection coefficient of plates (Hodge 2010) and this is the objective, among others, of further research of the authors of this article. The influence of the type of the surface has also been noticed by other authors such as (Lee and Ehsani 2008; Kuchmister et al. 2009).

For measurements in real conditions, the incidence angle has the greatest impact on the distance measurement if the energy centre of the spot of the laser beam doesn't coincide with the centre of the crosshairs of total station (total station doesn't rectified). This effect, similar to situation shown at Fig. 4, can be described by tangent function:

$$
\Delta d=p \cdot \operatorname{tg} \alpha
$$

where: $\Delta d$ - change of distance measurement [mm], $p$ - distance between the place indicated by the instrument crosshairs and the energy centre of the laser beam spot emitted by rangefinder, $\alpha$ - incidence angle of the laser beam on the target's surface.

The discrepancy between the aiming point and the distance measurement place increases with distance. That is why the effect of not parallelism of aiming line and laser beam, and the incidence angle of laser beam to the surface of the measured element will increase with the distance between total station and measuring point. For this reason, in the case of measurements (reflectorless or with reflectors: reflective foil or prisms) under large incidence angle, the measurements results should be interpreted with caution, depending on the expected accuracy of measurement.

In the case of measurements made on the reflective foil, it can work like a mirror. This can result in the inability to measure the distance or in measurement to item on which the laser beam was reflected.

\section{Summary}

The article presents the results of distance measurements $(D=30.00 \mathrm{~m})$ depending on the incidence angle of the laser beam to the surfaces of different roughness and colour. The possibility of changing the distance measurement by a glass element close to the aiming point was investigated as well. 
The measurements demonstrated lack of significant (within the accuracy of used total station) impact of incidence angle for reflectorless measurements made on matte surfaces. In the case of measurements made on the reflective foil it has been shown that for the angle greater than $50^{\mathrm{g}}$ $\left(45^{\circ}\right)$ the measurement may not be executed. In the case of reflectorless measurement to reflective foil reflection of laser beam can occur, and distance measurement will be made to a random point.

The surface roughness can affect distance measurement by overestimation of the measured distance. This is due mainly to the difference between defining where the surface of the material was and from where most of the light from the laser rangefinder was reflected.

Surface colour and reflectivity for radiation emitted by the laser rangefinder mainly affect the duration of the measurement (in the case of used total station but also of laser scanners, which can lead to a lack of registration of the points' location). If near the measuring point there are surfaces with different reflectivity (i.e. glass plate), the rangefinder will measure distance closer to the surface which reflects light better (due to greater intensity of reflected light). Evaluation how big is the influence on the distance measurement of colour surfaces is the subject of further research of the authors of this article.

\section{AKCNOWLEDGEMENT}

The authors would like to thank company TPI sp. z o.o. Office Gdańsk for sharing Topcon ES-107 total station, which was used during the tests.

\section{REFERENCES}

Beshr, A., Islam M., Abo E. 2011. "Investigating the Accuracy of Digital Levels and Reflectorless Total Stations for Purposes of Geodetic Engineering." Alexandria Engineering Journal 50 (4). Faculty of Engineering, Alexandria University: 399-405. doi:10.1016/j.aej.2011.12.004.

Bryś, H. 2012. "Refraktionseinflüsse Durch Elektrische Gleichstromfelder Influence of Current Power Line Electric Field on Refraction" 119: 2-9.

Coen, T.; Vanrenterghem, A.; Saeys, W.; De Baerdemaeker, J. 2008. “Autopilot for a Combine Harvester." Computers and Electronics in Agriculture 63 (1): 57-64. doi:10.1016/j.compag.2008.01.014.

Daliga, K. 2013. “Wpływ Przezroczystej Przegrody Na Pomiar Położenia Punktu Tachimetrem Z Elektrooptycznym Dalmierzem Impulsowym.” In GEODEZJA INŻYNIERYJNA Pomiary I Obliczenia, Przemieszczenia Budowli Oraz Obstuga Geodezyjna, edited by Zygmunt Kurałowicz, 1st ed., 7-26. Gdańsk.

Daliga, K.; Kurałowicz, Z. 2014. "Wpływ Przezroczystej Przegrody Na Wyniki Pomiarów Przemieszczeń W Badaniach Modelowych.” Inżynieria Morska I Geotechnika 5: 437-44.

Ehlert, D.; Heisig, M. 2013. "Sources of Angle-Dependent Errors in Terrestrial Laser ScannerBased Crop Stand Measurement." Computers and Electronics in Agriculture 93 (April). Elsevier B.V.: 10-16. doi:10.1016/j.compag.2013.01.002.

Hodge, R. 2010. "Using Simulated Terrestrial Laser Scanning to Analyse Errors in High- 
Resolution Scan Data of Irregular Surfaces." ISPRS Journal of Photogrammetry and Remote Sensing 65 (2). Elsevier B.V.: 227-40. doi:10.1016/j.isprsjprs.2010.01.001.

Kuchmister, J.; Mąkolski, K.; Ćmielewski, K.; Ćmielewski, B. 2009. "A Post for Precision Researches of Measurements of Distances by Reflectorless Tachymeter." Reports on Geodesy 2 (87).

Kyeong-Hwan, L.; Ehsani, R. 2008. "Comparison of Two 2D Laser Scanners for Sensing Object Distances, Shapes, and Surface Patterns.” Computers and Electronics in Agriculture 60 (2): 25062. doi:10.1016/j.compag.2007.08.007.

Prokop, A. 2008. "Assessing the Applicability of Terrestrial Laser Scanning for Spatial Snow Depth Measurements." Cold Regions Science and Technology 54 (3). Elsevier B.V.: 155-63. doi:10.1016/j.coldregions.2008.07.002.

Soudarissanane, S.; Lindenbergh, R.; Menenti, M.; Teunissen, P. 2011. "Scanning Geometry: Influencing Factor on the Quality of Terrestrial Laser Scanning Points." ISPRS Journal of Photogrammetry and Remote Sensing 66 (4). Elsevier B.V.: 389-99. doi:10.1016/j.isprsjprs.2011.01.005.

Recebido em Julho de 2015.

Aceito em Novembro de 2015. 